\title{
Positive-type Photosensitive Polyimide Based on Poly(amide acid), Vinyl Ether Crosslinker, and a Photoacid Generator
}

\author{
Masaki Okazaki, Hitoshi Onishi, Wataru Yamashita and Shoji Tamai \\ Material Design Unit, Material Science Laboratory, Mitsui Chemicals, Incorporated, \\ 580-32 Nagaura, Sodegaura-City, Chiba 299-0265, Japan
}

A positive-type photosensitive polyimide (PSPI) based on poly(amide acid) (PAA), 1,3,5-tris[(2-vinyloxy)ethoxy]benzene (TVEB) as a crosslinking dissolution inhibitor and a photoacid generator (PAG) has been developed. PAA was prepared from pyromellitic dianhydride (PMDA), 2,5(6)-bis(aminomethyl)bicyclo[2.2.1]heptane (NBDA) and 4,4'-oxydianiline (ODA) in $\mathrm{N}, \mathrm{N}$-dimethylacetamide (DMAc), which has moderate transparency above $365 \mathrm{~nm}$ and solubility for $1 \%$ sodium carbonate aqueous solution (aq.). Without isolation of PAA, the photosensitive resist solution was formulated with the polymerization solution ( $23 \mathrm{wt} \%$ in DMAc), TVEB ( $15 \mathrm{wt} \%$ for polymer) and PAG ( $3 \mathrm{wt} \%$ for polymer). No anomaly was recognized after the flexural endurance test by use of the 16 $\mu \mathrm{m}$ PSPI film, which was cured at $250^{\circ} \mathrm{C}$, on a Kapton $\otimes$ film. Furthermore a positive image featuring $30 \mu \mathrm{m}$ line and space patterns was observed by the contact mode when a $9 \mu \mathrm{m}$ thick film of the PSPI system was exposed to broadband UV light followed by development in a $1 \%$ sodium carbonate aq. at room temperature.

Keywords: positive-type, crosslinking dissolution inhibitor, photoacid generator, flexural endurance

\section{Introduction}

In recent years, there is an increasing demand for flexible wiring boards in association with diversification of electronic instruments, such as miniaturization, sophistication and so on. The coverlay, which is coated over a flexible wiring board for the purpose of protection of the circuit, is required to have thermal resistance, flexural endurance and electrical insulation properties. Polyimide films, which are excellent in thermal resistance, mechanical properties, flexibility, chemical resistance, electrical insulation properties, have been used up to now.

In particular, photosensitive polyimide (PSPI) [1] imparted with a photoresist function is a material attracting great interest, in view of shortening the fabrication process significantly. Due to the concern about the safety problems during operation or the environmental impact, a photosensitive resin which is capable of development using an aqueous alkali solution is strongly desired. So poly(amide acid) (PAA), which can be developed by dissolving in aqueous alkali solutions before thermal curing, and which has alkali-soluble carboxylic acid that disappears by ring-closure after thermal curing, is promising structure of photosensitive polyimide. Heretofore, there have been suggested a variety of alkaline developable negative and positive PSPI [2-13]. However, the high solubility of the PAA in alkali water causes problems such as that sufficient resolution cannot be achieved, the structure is restricted to particular structures only. Furthermore, although a film thickness of $10 \mu \mathrm{m}$ or greater is required to exhibit excellent insulation reliability, there is a problem of very low transparency for UV regions with this thickness, when conventional all aromatic PAAs are used.

Thus, solder resists for printed circuit board have been dominantly used as a photosensitive material that is capable of development in a dilute aqueous alkali solution, but it is difficult to say that the material, which is epoxy-acrylic-based, has sufficient flexibility or thermal resistance. 
In a previous paper[14], we reported the development of positive-type PSPIs based on semi-alicyclic PAA (Scheme 1, $\mathrm{m} / \mathrm{n}=100 / 0$ ), 1,1,1-tris(4-[2-(vinyloxy) ethoxy]phenyl)ethane (TVPE) (Scheme 2) as a crosslinking dissolution inhibitor, and N-trifluoromethyl sulfonyloxy-1,8-naphthaleneimide (TNI) as a photoacid generator. However a flexural endurance of polyimide film obtained from the PSPI was insufficient. In continuation to this study, the structure of a matrix PAA and vinyl ether compound, the loading content of it for photosensitivity was investigated to improve flexural endurance in this article. Furthermore, the lithographic evaluation of PSPI was also described.

\section{Experimental}

\subsection{Materials}

Pyromellitic

4,4'-oxydianiline

dianhydride

(PMDA),

2,5(6)-bis(aminomethyl)bicyclo[2.2.1]heptane

(NBDA) N,N-dimethyl -acetamide (DMAc) $\mathrm{N}$-trifluoromethyl

sulfonyloxy-1,8-naphthaleneimide (TNI) were obtained commercially and used as received.

\subsection{Synthesis of 1,3,5-tris[(2-vinyloxy)ethoxy] -benzene (TVEB) [15]}

Into a $300 \mathrm{ml}$ flask fitted with a mechanical stirrer, reflux condenser, thermometer, dropping funnel and nitrogen inlet, were placed 1,3,5-trihydroxybenzene (276.3 g, $2.19 \mathrm{~mol})$, DMSO $(3000 \mathrm{ml})$, and potassium carbonate $(1362.2 \mathrm{~g}, 9.9 \mathrm{~mol})$. The contents were stirred at $90{ }^{\circ} \mathrm{C}$ for $1 \mathrm{~h}$, and then 2-chloroethyl vinyl ether $(1050.0 \mathrm{~g}, 9.9 \mathrm{~mol})$ was added. After stirring at $90{ }^{\circ} \mathrm{C}$ for $7 \mathrm{~h}$, the reaction mixture was diluted with water, and transferred into a separatory funnel with $\mathrm{n}$-hexane. The organic layer was evaporated after extraction. Then the solid was recrystallized with methanol. The yield was $238.3 \mathrm{~g} \mathrm{(32.3 \% )}$. $\mathrm{IR}(\mathrm{KBr}) \quad v(\mathrm{~cm}-1): 1620(\mathrm{C}=\mathrm{C}), \quad 1600(\mathrm{Ph})$, 1200(C-O-C), 1H-NMR (DMSO) ppm: $3.96-4.26(\mathrm{~m}, 18 \mathrm{H}), 6.15(\mathrm{~s}, 3 \mathrm{H}), 6.55(\mathrm{q}, 3 \mathrm{H})$

\subsection{Polymer synthesis}

2,5(6)-bis(aminomethyl)bicyclo[2.2.1]heptane (NBDA) (m mol) and 4,4'-oxybisaniline(ODA) (n mol $)(m+n=0.5 \mathrm{~mol})$ in DMAc was added dropwise to a suspension of PMDA (109.1 g, 0.5 $\mathrm{mol})$ in DMAc $(300 \mathrm{ml})$ under nitrogen at $0{ }^{\circ} \mathrm{C}$ for $3 \mathrm{~h}$. The solution was stirred at room temperature for $12 \mathrm{~h}$. DMAc was added to prepare $23 \mathrm{wt} \%$ solution and filtrated with pressure. An inherent viscosity of the resulting polymer in DMAc was $0.62 \sim 0.82 \mathrm{dL} / \mathrm{g}$ at a concentration of $0.5 \mathrm{~g} / \mathrm{dL}$ in DMAc at $35^{\circ} \mathrm{C}$. IR(KBr) $(\mathrm{cm}-1): 1720(\mathrm{C}=\mathrm{O}$, carboxylic acid $), 1640(\mathrm{C}=\mathrm{O}$, amide $)$

\subsection{Dissolution rate}

The vinylether reagent was added to a polymer solution to study the effect of loading content. The polymer film spin-cast from the solution $(23 \mathrm{wt} \%$ concentration) on a silicon wafer was pre-baked at $80{ }^{\circ} \mathrm{C}$ for $10 \mathrm{~min}$ and then followed by post-baking at $100{ }^{\circ} \mathrm{C}$ for $5 \mathrm{~min}$. The films were subject to development in $1 \%$ sodium carbonate aq. at room temperature.

\subsection{Flexural endurance}

A both-sided plate was bent by $180^{\circ}$, and a load of $5 \mathrm{~kg}$ was applied on the bent part. This operation was repeated three times, and the presence or absence of peeling at the bend area was observed with an optical microscope.

\subsection{Measurements}

FTIR spectra were measured on a Jasco FT/IR-300 spectrophotometer. NMR spectrum was recorded on a JEOL-GSX270 spectrometer. Thermal analyses were performed on a SHIMADZU TGA-50 thermal analyzer at a heating rate of $10{ }^{\circ} \mathrm{C} / \mathrm{min}$ for thermogravimetry (TG) and a SHIMADZU TMA-50 at a heating rate of $10{ }^{\circ} \mathrm{C} / \mathrm{min}$ for thermal mechanical analysis (TMA) under air. Tensile test was carried out on SHIMADZU EZ-S at an extension rate of 30 $\mathrm{mm} / \mathrm{min}$. The film thickness was measured on a Dektak3 system (Veeco Instruments Inc.).

\section{Results and Disucussion}

3-1. Synthesis and properties of polymers

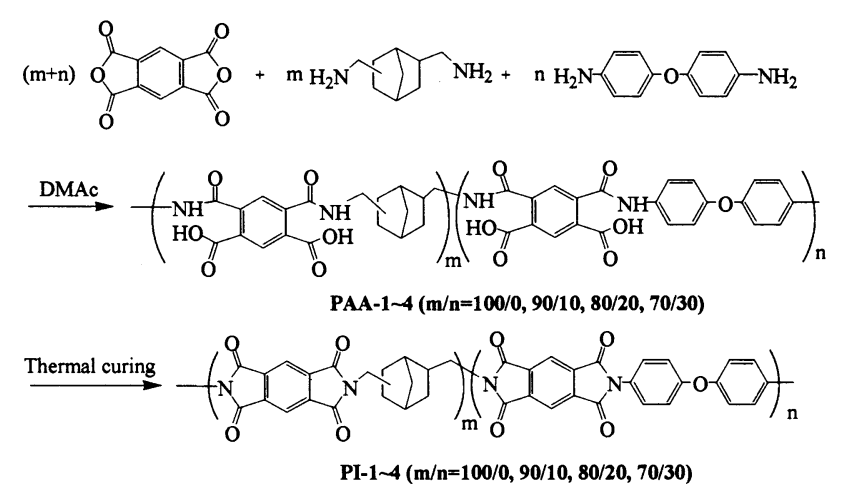

Scheme 1. Synthesis of polyimide (PI-1 4) 
Table 1. Properties of semi-alicyclic polyimide and co-polyimides

\begin{tabular}{|c|c|c|c|c|c|c|c|c|}
\hline Name & m:n & $\begin{array}{c}\text { Inherent viscosity } \\
\mathrm{dL} / \mathrm{g}\end{array}$ & $\begin{array}{c}\mathrm{Tg}^{\mathrm{b})} \\
{ }^{\circ} \mathrm{C}\end{array}$ & $\begin{array}{c}\text { Flexural } \\
\text { endurance }\end{array}$ & $\begin{array}{c}\text { Tensile strength }{ }^{\mathrm{c})} \\
\mathrm{MPa}\end{array}$ & $\begin{array}{c}\left.\text { Tensile modulus }{ }^{\mathrm{c}}\right) \\
\text { GPa }\end{array}$ & $\begin{array}{c}\text { Elongation }^{\mathrm{c})} \\
\%\end{array}$ & $\begin{array}{c}\text { Transparency }^{\mathrm{d})} \\
\%\end{array}$ \\
\hline PI-1 & $100: 0$ & 0.62 & 290 & 20 & 91 & 2.4 & 6 & 88 \\
\hline PI-2 & $90: 10$ & 0.64 & 290 & $>25$ & 60 & 1.8 & 4 & 40 \\
\hline PI-3 & $80: 20$ & 0.82 & 310 & $>25$ & 87 & 1.9 & 31 & 40 \\
\hline PI-4 & $70: 30$ & 0.70 & 320 & $>25$ & 85 & 2.5 & 48 & 10 \\
\hline
\end{tabular}

a) PI precursor (Poly(amide acid) was measured at a concentration of $0.5 \mathrm{~g} / \mathrm{dL}$ in DMAc at $35^{\circ} \mathrm{C}$.

b) Measured by thermal mechanical analysis at a heating rate of $10{ }^{\circ} \mathrm{C} / \mathrm{min}$

c) Measured by tensile test at an extension rate of $30 \mathrm{~mm} / \mathrm{min}$. d) Film thickness, $20 \mu \mathrm{m}$, transparency at $365 \mathrm{~nm}$.

At first flexural endurance properties of semi-alicyclic polyimide (PI-1: scheme 1, $\mathrm{m} / \mathrm{n}=100 / 0$ ) was investigated because the PSPI film which contains PI-1, TVPE (25 wt\% for polymer) and TNI (3 wt $\%$ for polymer) showed poor flexural endurance. PI-1 precursor (PAA-1) was prepared from PMDA and NBDA in DMAc and produced desired PAA-1 with inherent viscosity $0.62 \mathrm{dL} / \mathrm{g}$. PAA- 1 obtained here was readily converted to the corresponding polyimide by thermal treatment. By using the PI-1 film (20 $\mu \mathrm{m})$, flexural endurance test was carried out. A both-sided plate was bent by $180^{\circ}$, and a load of 5 $\mathrm{kg}$ was applied on the bent part. The crack observed when the test was repeated 20 times. As a result, it was found the flexural endurance of PI-1 is inferior to that of conventional all aromatic polyimide such as Kapton ${ }^{\circledR}$.

Thus the co-polymerization of NBDA and aromatic diamine was studied to improve flexural endurance. 4,4'-ODA was selected as a co-monomer, and co-poly(amide acid)s (Scheme 1, PAA-2 4, $\mathrm{m} / \mathrm{n}=90 / 10, \quad 80 / 20, \quad 70 / 30$ ) were synthesized in a same manner with PAA-1 synthesis. Polymerization was proceeded smoothly and produced desired PAA-2 4 with inherent viscosity $0.64 \sim 0.82 \mathrm{dL} / \mathrm{g}$ (Table 1 ). The polymers were identified as corresponding PAA-2 4 by IR spectroscopy. Each IR spectrum showed characteristic absorptions at 1720 and $1640 \mathrm{~cm}-1$ due to carboxyl acid and amide groups, respectively. PAA-2 4 was converted to the corresponding polyimide (PI-2 4) by thermal treatment and those thermal, flexural endurance and mechanical properties was investigated and summarized in Table 1. It was found the increasing of the content of 4,4'-ODA, glass transition temperature of PI was increased and flexural endurance was improved. Tensile test was carried out to get information of this behavior. Figure 1 showed the relationship between tensile strength and elongation on PI-1 4 films. Although strength and tensile modulus of each PIs are not so different, elongation behavior has quite different PI-1, 2 with PI-3,4. This result indicates that elongation gives good effect in flexural endurance.

The transparency of PAA-1 4 was also investigated in $20 \mu \mathrm{m}$ thickness. The increasing of the content of 4,4'-ODA, transparency was decreased (Figure 2). Thus PAA-3 was selected as a matrix PAA because of its adequate properties in

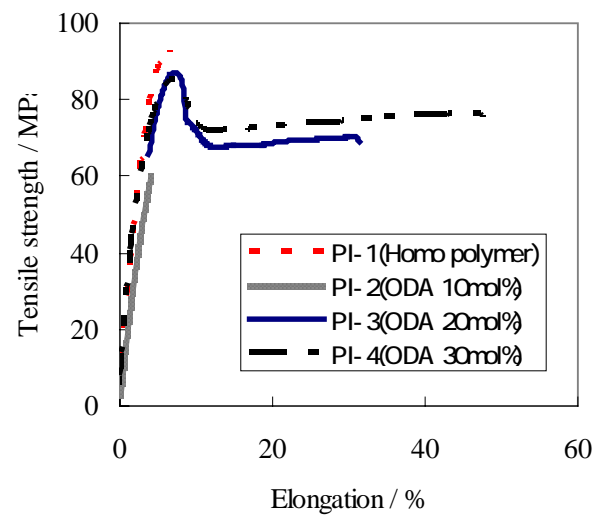

Figure 1. Relationship between tensile strength and elongation on PI-1 4 films.

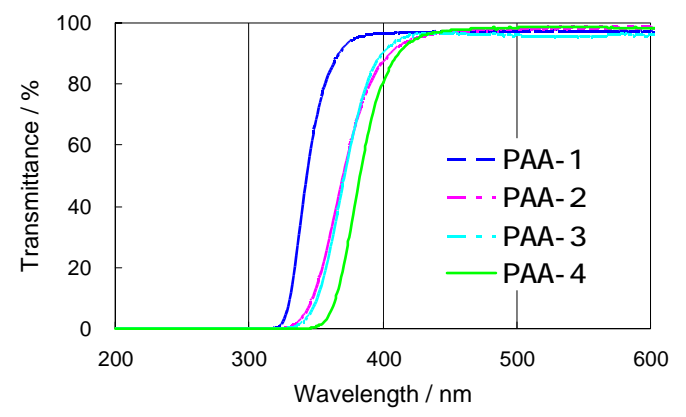

Figure 2. Transparency of PAA-1 4 in UV regions (20 $\mu \mathrm{m}$ thickness) 
both flexural endurance and transparency.

\section{3-2 Loading content of TVEB}

In previous report[14], TVPE was used as a crosslinking dissolution inhibitor. But 1,3,5-tris[(2-vinyloxy)ethoxy]benzene (TVEB) was adopted in this paper(Scheme 2) because this compound has not only low molecular weight per vinyl ether groups, but also low thermal degradation temperature (Td5) than TVPE (Table 2). That means it is possible to decrease loading content of vinyl ether compound, and the residue of it in film may be reduced after thermal curing.

a) TVPE

b) TVEB

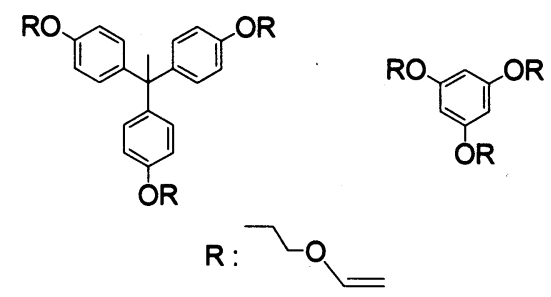

Scheme 2. Structure of vinyl ether compound

Table 2. Properties of vinyl ether compound

\begin{tabular}{|l|l|l|}
\hline & M.W. & Td5 ${ }^{\circ} \mathrm{C}$ a) \\
\hline TVPE & 516.6 & 325 \\
\hline TVEB & 336.4 & 222 \\
\hline
\end{tabular}

a) TGA analysis at a heating rate of $10^{\circ} \mathrm{C} / \mathrm{min}$

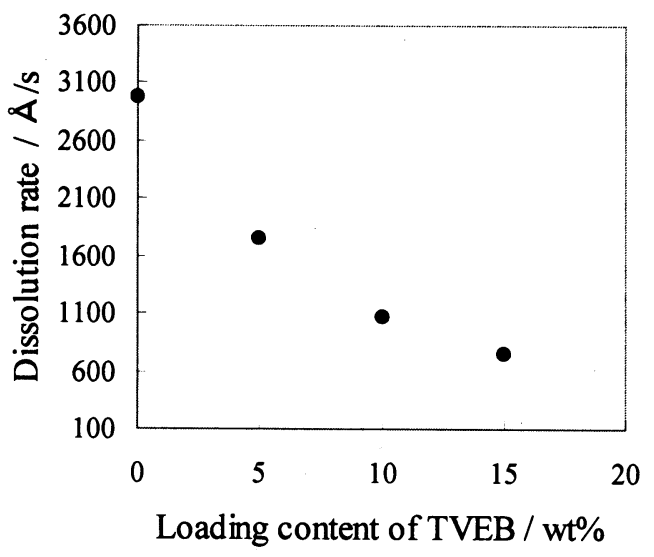

Figure 3. Effect of loading content of TVEB on dissolution rate for $1 \%$ sodiumu carbonate aq.

The effect of loading content of TVEB was studied. TVEB was added to $23 \mathrm{wt} \%$ PAA-3 solution in DMAc, and the film spin-cast on a silicon wafer was pre-baked at $80^{\circ} \mathrm{C}$ for $10 \mathrm{~min}$ and post-baked at $100^{\circ} \mathrm{C}$ for $5 \mathrm{~min}$ and developed with $1 \%$ sodium carbonate aq. The dissolution rate was estimated by measuring the change of film thickness after the development. Figure 3 showed the relationship between the loading content of TVEB and the dissolution rate of the film consisting of PAA-3 and TVEB. The dissolution rate was decreased gradually with increasing TVEB content, and reached below $1000 \AA / \mathrm{s}$ when TVEB was added $15 \mathrm{wt} \%$. Thus the loading content of TVEB was determined to be $15 \mathrm{wt} \%$ for PAA-3.

\subsection{Flexural endurance of PSPI composition}

A $16 \mu \mathrm{m}$ film on a Kapton $®$ film was prepared by using a solution of the positive PSPI composition consisting of PAA-1 or PAA-3, TVEB (15 wt $\%$ for polymer) and TNI (3 wt $\%$ for polymer). Imidation of coating film was conducted by heating from room temperature to $250^{\circ} \mathrm{C}$ for 2 hours, and at $250^{\circ} \mathrm{C}$ for 2 hours. Flexural endurance test was performed in a same manner as describe in section 3.1. That operation was repeated three times. Although crack observed on PSPI based on PAA-1, no anomaly was recognized after the test using the film consisting of PAA-3 and photosensitizer. It was found the flexural endurance of PSPI film was improved by introduction of 4,4'-ODA and optimization of vinyl ether compound.

\section{3-4 Lithographic evaluation}

The photosensitive polymer system was formulated by adding TVEB and TNI to PAA-3 polymerization solution. The effect of post-exposure bake (PEB) temperature on the dissolution rate in $1 \%$ sodium carbonate aq. was studied. The big difference in dissolution rate between the exposed and the unexposed area was observed over $100{ }^{\circ} \mathrm{C}$ for $5 \mathrm{~min}$. After these preliminary optimization studies involving TVEB loading, PEB temperature and developing conditions, a photosensitive polyimide system consisting of PAA-3, TVEB, and TNI was prepared. Figure 4 presents a laser scanning microscopy of the contact-printed image after exposure of $400 \mathrm{~mJ} / \mathrm{cm} 2$ light, followed by development with $1 \%$ sodium carbonate solution. Positive patterns with $30 \mu \mathrm{m}$ resolution were obtained when a $9 \mu \mathrm{m}$ thick film was used. 


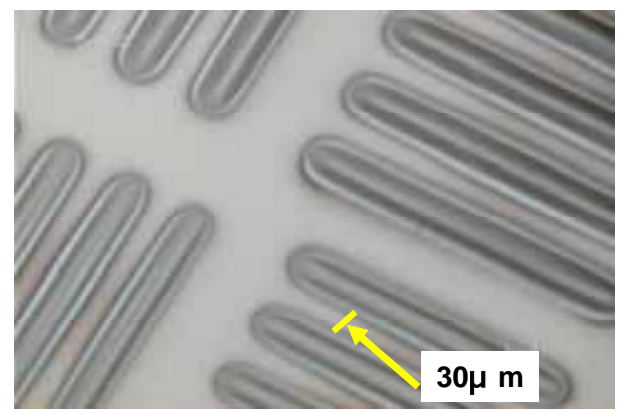

Figure 4. Laser scanning microscopy image of PSPI (thickness: $9 \mathrm{~mm}$ )

\section{Conclusion}

PAA-3 prepared from pyromellitic dianhydride (PMDA),

2,5(6)-bis(aminomethyl)bicyclo[2.2.1]heptane

(NBDA) and 4,4'-oxydianiline (ODA) (NBDA $\left./ 4,4^{\prime}-\mathrm{ODA}=80 / 20\right)$ in $\mathrm{N}, \mathrm{N}-$

dimethylacetamide (DMAc) has moderate transparency above $365 \mathrm{~nm}$ and solubility for $1 \%$ sodium carbonate aqueous solution (aq.). Without isolation of PAA-3, the photosensitive resist solution was formulated with the polymerization solution (23 wt\% in DMAc), TVEB (15wt\% for polymer) and PAG (3 wt $\%$ for polymer). No anomaly was recognized after the flexural endurance test by use of the $16 \mu \mathrm{m}$ PSPI film, which was cured at $250^{\circ} \mathrm{C}$, on a Kapton ${ }^{\circledR}$ film. It was found the flexural endurance of PSPI film was improved by introduction of ODA and optimization of vinyl ether compound. Furthermore, a positive image featuring $30 \mu \mathrm{m}$ line and space patterns was observed by the contact mode when a $9 \mu \mathrm{m}$ thick film of the PSPI system was exposed to broadband UV light followed by development in a $1 \%$ sodium carbonate aq. at room temperature.

\section{References}

1. Ghosh, M. K., Mittal, K. L., Eds. Polyimides Fundamentals and Applications; Marcel Decker: New York, 1996.

2. Ueda M, Nakayama T. Macromolecules 1996; 29: 6427.

3. Watanabe Y, Fukukawa K, Shibasaki Y, Ueda M. J. Polym Sci., Part A: Polym. Chem. 2005; 43: 593.

4. Fukukawa K, Shibasaki $\mathrm{Y}$ and Ueda M. Polym.Adv.Technol. 2006; 17:131.

5. Kubota S, Moriwaki T, Ando T, Fukami A. J. Appl. Polym.Sci. 1987; 33: 1763.

6. Omote T, Mochizuki H, Koseki K, Yamaoka T. Macromolecules 1990; 23: 4796.

7. Mochizuki A, Teranishi T, Ueda M. Polym. J. 1994; 26:315.

8. Mochizuki A, Teranishi T, Ueda M, Matsushita K. Polymer 1995; 11: 2153.

9. Nakayama T, Mochizuki A, Ueda M. React. Funct. Polym. 1996; 30: 109.

10. Nakano T, Iwasa H, Miyagawa N, Takahara S, Yamaoka T. J. Photopolym. Sci. Technol. 2000; 13: 715.

11. Moss MG, Cuzman RM, Brewer T. Advances in Resist Technology and Processing VI, Proc. SPIE, Soc. Opt. Instr. Eng. 1989; 1086: 396.

12. Hayase S, Takano K, Mikogami Y, Nakano Y. J. Electrochem. Soc. 1991; 138: 3525.

13. Omote T, Yamaoka T. Polym. Eng. Sci. 1992; 32: 1634.

14. Okazaki M, Onishi H, Yamashita W and Tamai S. J. Photopolym. Sci. Technol. 2006; 19: 277.

15. Moon, S.; Chung, C.; Yamaoka, T.; Polymer, 41, 4013, (2000). 